\title{
Human-climate induced drivers of mountain grassland over the last 40 years in Sidama, Ethiopia: perceptions versus empirical evidence
}

Denbeshu Debeko ${ }^{1}$, Ayana Angassa $^{3^{*}}$, Aster Abebe$^{1}$, Ashenafi Burka $^{2}$ and Adugna Tolera ${ }^{1}$

\begin{abstract}
Background: Mountain grasslands are globally important ecosystems. They are considered as heritage sites with "outstanding values" to ecological communities by adding a further "layer and support to the existing protection measures." However, mountain grasslands are increasingly under threat from human activities and impacts of climate change.

Methods: Using satellite imagery, we studied land use/land cover (LULC) patterns between 1973 and 2015. Individual interviews consisting of 240 households for comparison and field data collection were conducted for accuracy assessment.

Results: Five categories of LULC types were identified from the image classification that included forestland, grassland, shrubland, bushland, and agricultural land. Between 1973 and 2015, the forestland, grassland, and shrubland covers were declined by $15.9 \%, 53.6 \%$, and $41.0 \%$, respectively. In contrast, bushland and agricultural land were increased by $169 \%$ and $647 \%$, respectively. The overall LULC classification accuracies for the four reference years ranged from 77.6 to $86.5 \%$ with Kappa statistic of 0.69 to 0.80 . The majority of respondents ( 92 . $5 \%$ ) mentioned that the cover of forestland outsized the other land use land cover types followed by grassland in the past.

Conclusions: The stated indicators of land use/land cover changes linked to the impact of climate change were decline in milk yield and crop production, spread of livestock diseases, degradation of grazing lands, and change in the timing of rain. The results of the study suggest that human-climate related components were major drivers of land use/land cover dynamics that demand for proper management and conservation of mountain grassland ecosystem in Sidama South Ethiopia.
\end{abstract}

Keywords: Land use/land cover, Landsat, Remote sensing, Change detection, Mountain grassland, Sidama, Household survey

\footnotetext{
*Correspondence: ayana.angassa@gmail.com

${ }^{3}$ Department of Animal Science and Production, Botswana University of

Agriculture and Natural Resources, Private Bag 0027, Gaborone, Botswana

Full list of author information is available at the end of the article
} 


\section{Background}

Mountain grasslands are globally important ecosystems. They are considered as heritage sites with "outstanding values" to ecological communities by adding a further "layer and support to the existing protection measures" (Thorsell 2002). Furthermore, mountain grasslands are regions of high diversity and species-rich ecosystems that co-evolved with centuries of livestock grazing (Spiegelberger et al. 2006). Climate change has the potential to alter these ecosystems and the services they provide to each other and to human society at large. Human societies depend on ecosystem provisioning, regulating, cultural, and supportive services for their own security. Thus, mountain grassland ecosystems provide many of the important goods and services for human beings including food, timber, fresh water, protection from natural hazards, carbon storage, and many other functions including recreation and tourism (Messerli and Ives 1997). They also provide forage for grazing animals and habitat for varieties of wild animals. The ecosystem goods and services from mountain grasslands are relied upon by some of the most impoverished people in the world who are often marginalized due to cultural factors and inaccessibility of most mountain areas (Gerlitz et al. 2012).

According to a recent study (Ward et al. 2014), mountain grasslands also store considerable amounts of carbon and these ecosystems should be accounted for climate policy. However, mountain grasslands are increasingly under threat from human activities (Körner et al. 2005) and impacts of climate change (Schroter et al. 2005). Besides, changes in land use such as increases in human settlements in the high mountain areas and the gradual degradation of remote sites threaten the unique biodiversity of mountain ecosystems (Spiegelberger et al. 2006). The floristic composition and species diversity of mountain grasslands are changing generally in response to human-induced factors (Spiegelberger et al. 2006). The magnitude of changes in mountain grasslands is linked to ecosystem processes and excessive interferences by human beings and over-exploitation of these ecosystems.

Human activities have modified mountain grassland ecosystems in the process of food production and other essentials for several thousands of years (Ellis and Pontius 2007). In recent years, the rates, extent, and intensity of human pressure on mountain grasslands are by far greater than before, affecting the functioning of these ecosystems. These affect consecutively the functional attributes of ecosystems, the provision of ecosystem services, and human welfare (Ellis and Pontius 2007).

Earlier evidences (Beniston and Rebetez 1996; Beniston et al. 1997; Theurillat and Guisan 2001; Nogue's-Bravo et al. 2007) have shown that mountain grassland ecosystems are disproportionately exposed to the impact of climate change. This is of great concern in the face of climate change as mountain grassland ecosystems represent irreplaceable resources, both in terms of biodiversity conservation and the ecosystem services they provide (Körner et al. 2005; Viviroli and Weingartner 2004). Climate is an integral part of mountain ecosystems and organisms have adapted to their local climate over time. The goods and services provided by mountain ecosystems sustain almost half the human population worldwide, and also maintain the integrity of the Earth's ecosystem through the provision of vital environmental regulation and rejuvenation functions (Karma et al. 2010).

Despite the importance of mountain grassland ecosystems worldwide, no previous studies have examined the mechanisms involved in land use/land cover changes in mountain grasslands of Sidama in South Ethiopia. In order to assess the potential impacts of human activities and climate change on trends of grassland ecosystems, a commonly employed method could be the use of a remotely sensed image on land use/land cover changes (Abate and Angassa 2016). This article presents humanclimate induced drivers on trends of mountain grassland in Sidama Zone in South Ethiopia between 1973 and 2015 using earth-observing satellite imagery and perceptions of the local communities with the objectives of (1) determining the driving forces of land use/land cover changes, (2) understanding the perception of local communities on land use/land cover changes between 1973 and 2015, and (3) establishing and mapping the magnitude, rates, nature, and spatial distribution of land use/ cover types that occurred in the study area.

\section{Methods}

\section{Study area}

The study was conducted in Bursa and Wonsho districts of Sidama Zone, South Nations Nationalities and Peoples Regional State (SNNPRS) of Ethiopia. The study area covers about 2800 ha comprising three Kebeles (i.e., the lowest administrative unit in Ethiopia) in two adjacent watershed areas, namely Lalta and Kolla. Two of the three Kebeles, Mollona-Meno and Chulule, are located in Bursa District, whereas the third kebele known as Orowo is found in Wonsho District. All the three Kebeles are assumed to represent the Ethiopian highlands in sub-afroalpine vegetation Zone in general and the Sidama highlands in particular (Fig. 1). The study area is located between latitudes of $6^{\circ} 41^{\prime} 19^{\prime \prime}$ and $6^{\circ} 44^{\prime} 52^{\prime \prime} \mathrm{N}$, and longitudes of $38^{\circ} 33^{\prime} 52^{\prime \prime}$ to $38^{\circ} 35^{\prime} 59^{\prime \prime} \mathrm{E}$ at an altitude range between 2749 and $3172 \mathrm{~m}$ above sea level.

The topographies of the study areas are mountainous and hilly, with slope percentages ranging from 10 to $45 \%$. The mean annual rainfall is about $2000 \mathrm{~mm}$, whereas the mean annual temperature varies between 10 and $15{ }^{\circ} \mathrm{C}$. The area receives bi-modal rainfall with the short rainy season or the Belg rain occurring from 


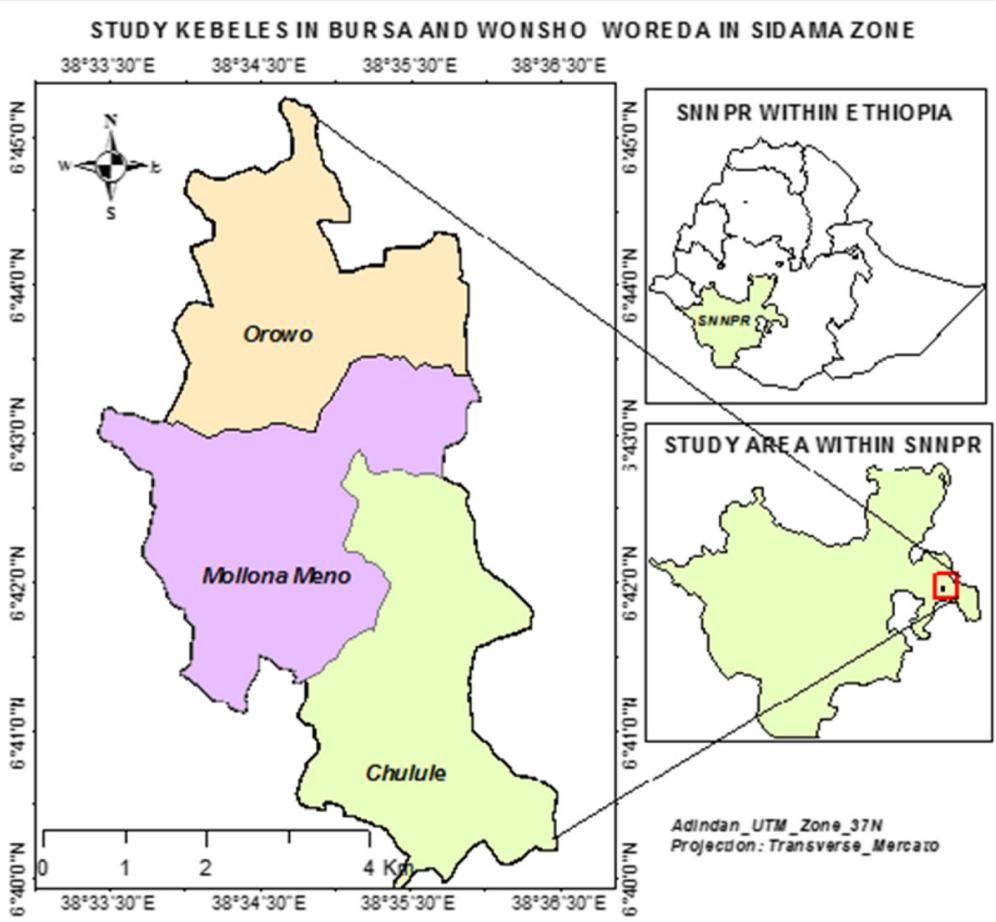

Fig. 1 Map of the study area in Sidama highland, Southern Ethiopia

March to May and the main rainy season or the Kremt rain occurring from June to October (Bursa District Ministry of Agriculture office (MoA) 2014).

The study areas are occupied by low forests and grasslands. The vegetation is characterized by trees, bushes, and shrubs. Some of these included Erica arborea, Hagenia abyssinica, Ilex mitis, Hypericum revolutum, Juniperus procera, Yushania alpina (the giant grass/bamboo), Rubus steudneri, Discopodium penninervium, Dombeya schimperiana, Vernonia auriculifera, and Phytolacca dodecandra.

\section{Sampling and survey approach}

The survey was carried out in February 2016. A total of 240 household $(\mathrm{HH})$ heads, i.e., $80 \mathrm{HH}$ heads per Kebele, were selected purposively for individual interview. Only seven female respondents were represented in the present survey due to few female-headed $\mathrm{HHs}$ in the study area. Age was one of the criteria in the selection of $\mathrm{HH}$ heads for the interview. We selected $\mathrm{HH}$ heads aged 55 years old and above so that they can easily recall and tell trends of environmental changes over the last $40-50$ years. The survey was conducted in two phases. Firstly, field observations were undertaken to understand the different classes of land use and gather information on the background of the study areas for instance farming systems such as crop farming and livestock production. This was followed by preparation and pre-testing of a semi-structured questionnaire, which consists of a mix of unstructured and structured questionnaires (i.e., questionnaire that contains both open-ended and closedended questions). Secondly, the information gathered during the first phase of the field visit was used to redesign the semi-structured questionnaire to collect qualitative and quantitative data. Semi-structured face-to-face $\mathrm{HH}$ heads interviews were conducted to gather information on trends, factors facilitating land use/land cover changes, and indicators used by the local farmers to tell information on climate change and its impacts, as well as current land management practices and socio-economic conditions of the local communities in the mountain grasslands of Sidama Zone. In this paper, drivers of land use change refers to climateand human-related factors that directly/indirectly impact the processes of land use change and associated resources, such as soil, water, and biodiversity, while local indicators refers to farmers way of understanding changes in climate and land use changes. The questionnaire covered a wide range of socio-economic conditions that included (1) land size, (2) land-use types and trends of environmental changes over the last 40-50 years, and (3) communities' perceptions on drivers of land use/cover changes. Generally, data were kept safe and secure at all stages of research process and entered into a computer for data analysis.

\section{Data analysis on households interview}

We used Statistical Package for Social Sciences (SPSS) version 20 (SPSS Inc. 2008) software to analyze the household survey data. Descriptive statistics such as 
cross-tabulation, frequencies, and percentage values were employed to summarize the qualitative data set.

\section{Specifications of satellite data and preparation}

The data used in the current study were classified into satellite data and data based on ground truth in terms of land use classes. The ground truth data were in the form of reference data points collected using global navigation satellite system (GNSS) in February 2016 for the 2015 map of land use/cover changes. Satellite image data for a period of 4 years that consisted of multi-spectral scanner (MSS) data acquired by Landsat satellite 1 on 31/01/1973, Thematic Mapper (TM) data acquired by Landsat 5 on 21/01/ 1986, Enhanced Thematic Mapper plus (ETM+) data acquired by Landsat 5 on 05/02/2000, and operational land imager (OLI) and thermal infrared sensor (TIRS) data acquired by Landsat 8 on 23/12/2015 (Fig. 2). All data were downloaded from "Global Land Cover Facility" (http:// glcfapp.glcf.umd.edu:8080/esdi/) and "Earth Explorer" (http://earthexplorer.usgs.gov/) websites. Specifications of the satellite data acquired for change analysis are given in Appendix 1.

\section{Image pre-processing and classification}

Collection of different episodic years of satellite image data was the initial stage for image processing and analysis. Multi-temporal rectified Landsat images were downloaded from "Global Land Cover Facility" and "Earth Explorer" websites. Landsat satellite images of the year 1973, 1986, 2000, and 2015 having a map projection of Universal Transverse Mercator (UTM) zone 37 and datum WGS84 were pre-processed using Earth Resources Data Analysis System (ERDAS) Imagine 2014 software in order to well-match the image with other ancillary data (Fig. 2). Satellite image register an exhaustive data of features on the ground at the time of data acquisition. As a pre-processing stage, layer stacking (compiling of different bands) and sub-setting were done on the different images. Then, digital image enhancement and interpretation techniques were used to make the interpretation of the data easier. The main image processing started with selecting sample sites using the field GNSS data and all the available images were classified into five classes (i.e., forestland, grassland, shrubland, bushland, and agricultural land) by applying supervised classification method and maximum likelihood algorithm. After the land use/cover changes classification of the years 1973, 1986, 2000, and 2015, the classification results were evaluated by employing accuracy assessment technique to examine how the results reflect the reality on the ground. Besides, the conversion matrix analysis was conducted to investigate the source and destination of land use/cover changes. Descriptions of land use/land cover changes are given in Appendix 2.

\section{Land change detection}

A post-classification detection method was employed to perform land use/land cover change detection. According to Singh (1989), change detection is the process of identifying differences in the state of an object or phenomenon by observing it at different times. Lu et al. (2004) indicate that detection of changes in land-cover patterns is extremely important for understanding relationships and interactions between human and natural phenomena in order to make decision concerning the management and conservation of the natural environment. A pixel-based comparison was used to produce change information on pixel basis and thus, interpret the changes more efficiently taking into account the advantage of "-from, -to" information. Classified image pairs of two different decades' data were compared using cross-tabulation in order to determine the qualitative and quantitative aspects of land use change between 1973 and 2015. A change matrix (Weng 2001) was produced with the help of ERDAS Imagine software. Quantitative areal data of the overall land use/cover changes as well as gains and losses between 1973 and 2015 in each category were compiled. Maps were paired (19721986, 1986-2000, and 2000-2015) and overlaid in a geographic information system (GIS) in order to produce three cross-tabulation matrices that combined classes among the three pairs of periods to produce areas.

The diagonal of each matrix showed the area of land that remained unchanged during each period: this is the so-called persistence in the landscape. The off-diagonal combinations account for the patches that were transformed from one category into another. Gain, loss, absolute value of net change, swap, and total change were calculated for each class according to the method of Pontius et al. (2004). The gains are the differences between the column totals and persistence while the losses are between row totals and persistence. With respect to loss-to-persistence ratios (lp), values higher than 1 indicate a greater tendency of transition to other land use land cover (LULC) class rather than stability, which is a measure of the vulnerability to transition (Braimoh 2006). Gain-to-persistence ratio (gp), if a value is higher than 1 , it indicates a greater tendency of LULC types to gain rather than to persist (Braimoh 2006). The absolute value of net change was, therefore, the modulus of the difference between time 1 and time 2. Swap was a component of changes that imply that a given area of a category is lost at one location, while the same area is gained at a different location. Swap was calculated as twice the minimum of the gain and loss, since each gained pixel is paired with a lost pixel to create a pair of pixels that swapped. Finally, the total change was either the sum of the net change and the swap or the sum of the gains and losses. Gain-to-persistence ratio ( $\mathrm{gp}=$ gain/persistence), 


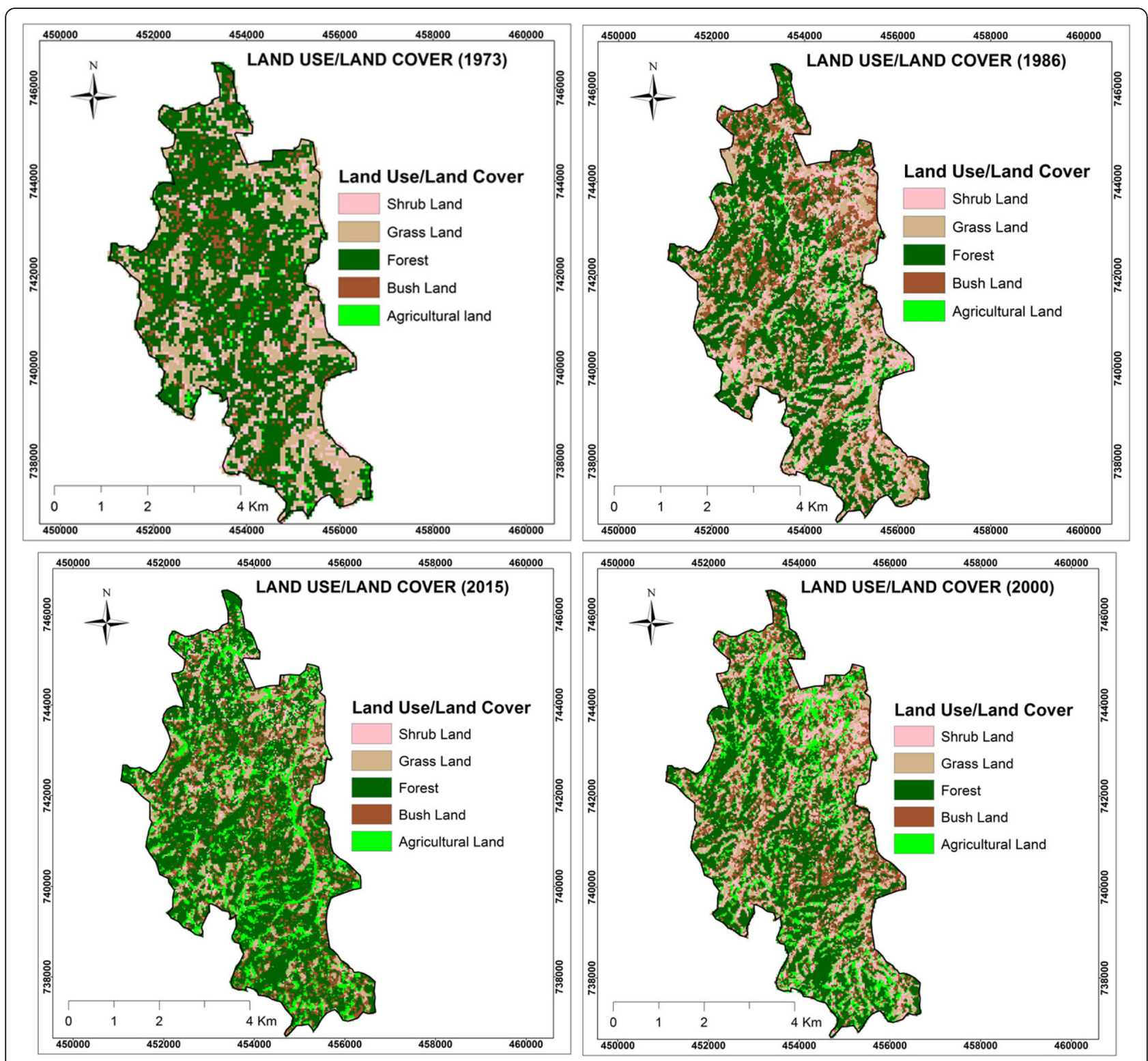

Fig. 2 Land use/land cover map of Sidama highland in southern Ethiopia in 1973, 1986, 2000, and 2015

loss-to-persistence ratio (lp $=$ loss $/$ persistence), and net change-to persistence ratio $(\mathrm{np}=\mathrm{gp}-\mathrm{lp})$ were also calculated in order to evaluate the persistence characteristics of the different LULC classes (Braimoh 2006). Systematic transitions were identified by comparing off-diagonal changes to the expected values of change, considering random processes of gain or loss. A process of gain was considered random if the gaining category replaced others proportionally to the area of those other categories at time 1 . Therefore, a category that gained would randomly replace a larger percentage of a large category and a smaller percentage of a small category. Equation (1) gives the expected transition from class $i$ to class $j(G i j)$, where $P \cdot j$ is the column total of category $j$ in the transition matrix and denotes the percentage of the landscape in category $j$ at time $2, \mathrm{Pjj}$ is the persistence of category $\mathrm{j}, \mathrm{Pi} \bullet$ is the row total of category $i$ and represents the percentage of the landscape found in category $\mathrm{i}$ at time 1 , and, finally, $\mathrm{Pj} \bullet$ is the row total for category $j$, which denotes the percentage of the landscape in category $j$ at time 1.

$$
\mathrm{Gij}=(\mathrm{P} \bullet \mathrm{j}-\mathrm{Pjj}) \times \mathrm{Pi} \bullet / 100-\mathrm{Pj} \bullet
$$

Conversely, a process of loss is random when the losing category is replaced by others proportionally to the area of those other categories at time 2. In this case, a category that loses would be replaced randomly to a 
greater extent by a large category and to a lesser extent by a small category. Equation (2) gives the expected transition from class $i$ to $j$ (Lij), where $\mathrm{Pi} \bullet$ is the row total of category $\mathrm{i}$, Pii is the persistence of category i, P - $j$ is the column total of category $j$, and $P \bullet i$ is the column total for category i.

$$
\mathrm{Lij}=(\mathrm{Pi} \bullet-\mathrm{Pii}) \times \mathrm{P} \bullet \mathrm{j} / 100-\mathrm{P} \bullet \mathrm{i}
$$

Any large deviation from the expected values was considered to represent a systematic landscape change. Finally, the fact that class $\mathrm{X}$ systematically gained from class $\mathrm{Y}$, while class $\mathrm{Y}$ systematically lost to class $\mathrm{X}$, gives conclusive evidence of a dominant signal of landscape transformation (Braimoh 2006). The classified images were compared in three periods, i.e., 1973-1986, 19862000, and 2000-2015. Change statistics were computed by comparing image values of one data set with the corresponding value of the second data set in each period. LULC conversion matrix between 1973 and 2015 was generated using ArcGIS 9.1 software and compiled in a matrix table, and the values were presented in terms of hectares.

\section{Accuracy assessment}

Accuracy assessments determine the quality of the information derived from remotely sensed data. The product of image classification is land cover maps. Their accuracy needs to be assessed so that the ultimate user is made aware of the potential problems associated with their use. Evaluation of the accuracy of a classification may be undertaken for each of the categories identified and its confusion with other covers, as well as for all the categories. The outcome of accuracy assessment is usually presented in a table that reveals accuracy for each cover category and for all categories as a whole.

Assessment of classification accuracy of the different images between 1973 and 2015 was carried out to confirm the quality of information derived from the data. According to Owojori and Xie (2005), if the classification data are to be useful in detecting change analysis, it is essential to perform accuracy assessment for individual classification. For the accuracy assessment of land cover maps extracted from satellite images, stratified random sampling method was used to represent the different land cover classes in the study areas. The accuracy assessment was carried out using 70 random points for each class, which was based on ground truth data and visual interpretation. Comparison of reference data and classification results were carried out statistically using error matrices. In addition, a non-parametric Kappa test was also performed to measure the extent of classification accuracy as it not only accounts for diagonal elements but also for all the elements in the confusion matrix (Rosenfield and Fitzpatirck-Lins 1986). Kappa is a measure of agreement between predefined producer ratings and user assigned ratings. It is calculated by the formula: $K=P(A) P(E) / 1 P(E)$, where $\mathrm{P}(\mathrm{A})$ is the number of times the $K$ raters agree, and $P(E)$ is the number of times the $K$ raters are expected to agree only by chance (Gwet 2002; Viera and Garrett 2005).

\section{Results}

\section{Driving forces of land use/cover changes}

Respondents perceived that the major drivers of land use/cover changes in the study area were multifaceted. Some of the emergent drivers forwarded by respondents included frequent droughts, extended timing of rain, changes in seasonal weather conditions, and expansion of cultivation, increased population pressure, land tenure changes, deforestation, soil erosion, land degradation, and overgrazing (Fig. 3). Among these, most respondents (94.2\%) mentioned that frequent droughts and extended timing of rain were the major drivers (Fig. 3). Similarly, about $91.3 \%$ of respondents perceived that soil erosion and continued land degradation were among major contributors to land use/cover changes (Fig. 3).

\section{Local indicators of climate change}

Local perceptions showed that declines in water availability, loss of grazing areas, and reduced milk production were key indicators of land use/cover changes. Respondents further emphasized that the prevalence of livestock diseases and downward trends in livestock holdings per household were additional indicators of land use/cover changes over the last four to five decades (Fig. 4). Respondents also mentioned that reduced vegetation cover, decline in honey production, change in the timing of rain, extended dry period, dried up of wet lands, and reduced crop yields were additional indicators of land use/cover changes (Fig. 4). Primarily, respondents believed that change in the timing of rain (94.2\%), increased temperature (94.2), and prevalence of livestock diseases (94.6\%) were key indicators of land use/ cover changes (Fig. 4). Generally, respondents believed that the rise in temperature and reduced rainfall from 1973 to 2015 had accelerated the magnitude of land use/cover changes in the study areas.

\section{Perceptions of local communities on land use/cover changes}

The results showed declining trend in land holdings per household over the last 40 to 50 years (Table 1). The majority of respondents (90\%) perceived that land use/ cover changes were a reflection of shifts in the size of grazing lands and feed availability for animals (Table 2). Most respondents (96.7\%) considered leaves of trees and mountain bamboos as major sources of feeds for livestock despite shrinkage of grazing lands (Table 2). About 


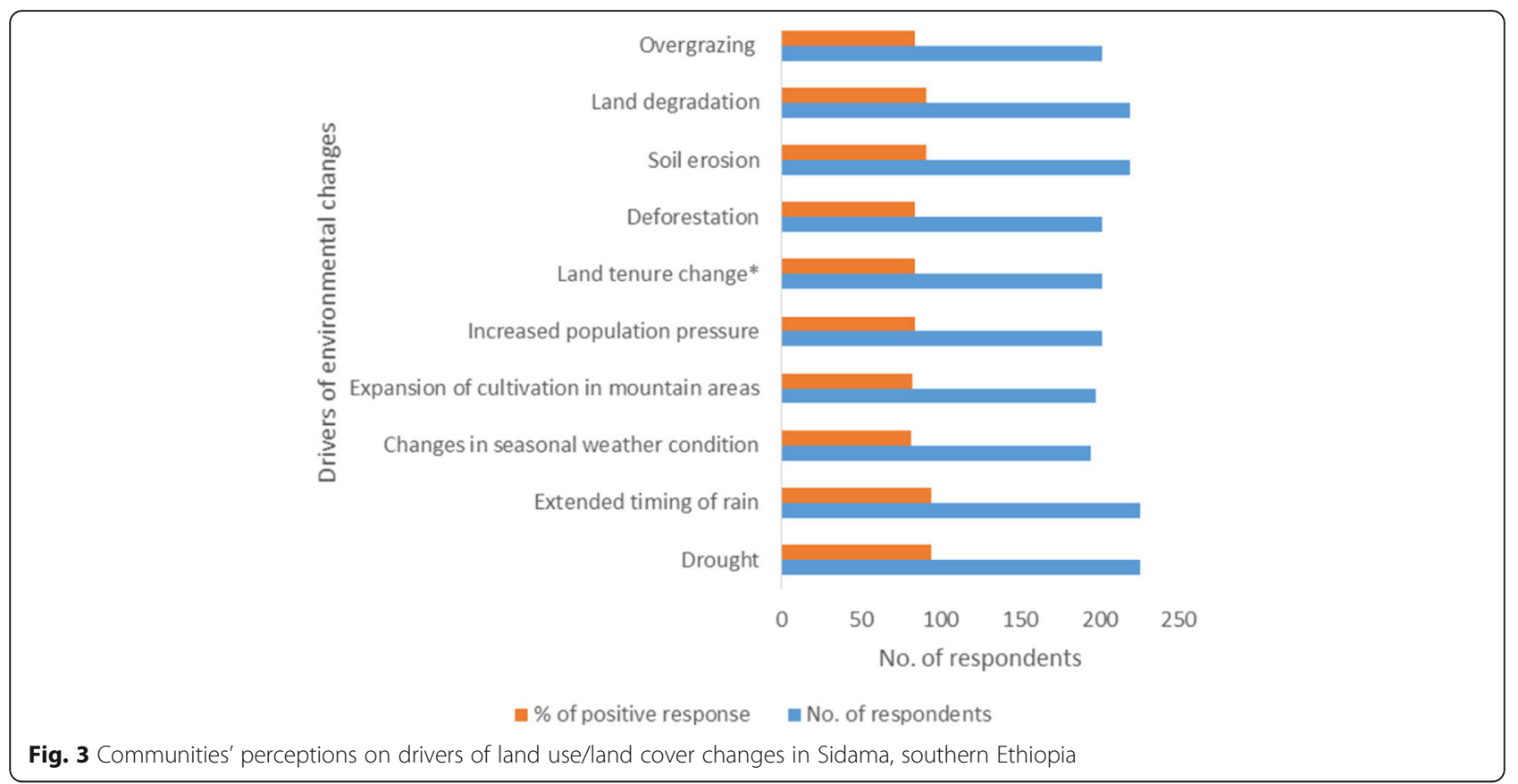

92.5\% of respondents believed that vast mountain areas were covered with forests and grasslands some 40 to 50 years ago (Table 2). One the other hand, respondents $(94.2 \%)$ stated that grazing pressure was very low in the past four to five decades as compared to the present condition. They also reported that crop yield per unit area was reduced attributed to increased soil erosion (Table 2). Despite the decline in crop yield, most lands were covered by crops and vegetables as mentioned by respondents.

\section{Classification, magnitude, and rate of land use/cover changes}

Figure 5 shows the landscape composition of the study areas in terms of land use/cover changes between 1973 and 2015. The current analysis showed that agricultural land was about 59.1 ha ( $2 \%$ of the studied landscapes) in 1973 (Fig. 5). The results displayed that landscape covered by agriculture was the second most dominant land use types in 2015, which is accounting for $16 \%$ of the total land area (Fig. 5). Bushland cover showed an increase from 6\% in 1973 to $16 \%$ in 2015 (Fig. 5). However, the forestland and grassland covers showed a decline from $58 \%$ and $22 \%$ in 1973 to $50 \%$ and $11 \%$ in 2015 , respectively.

Figure 6 presents patterns of land use/cover dynamics in Sidama mountain grasslands in South Ethiopia. The existing analysis showed a decline in forestland cover from 1643.02 ha in 1973 to 1381.79 ha in 2015 (Fig. 5). Similarly, the grassland and shrubland covers showed a considerable amount of reduction between 1973 and 2015 (Figs. 5 and 6). In contrast, bushland cover increased in size

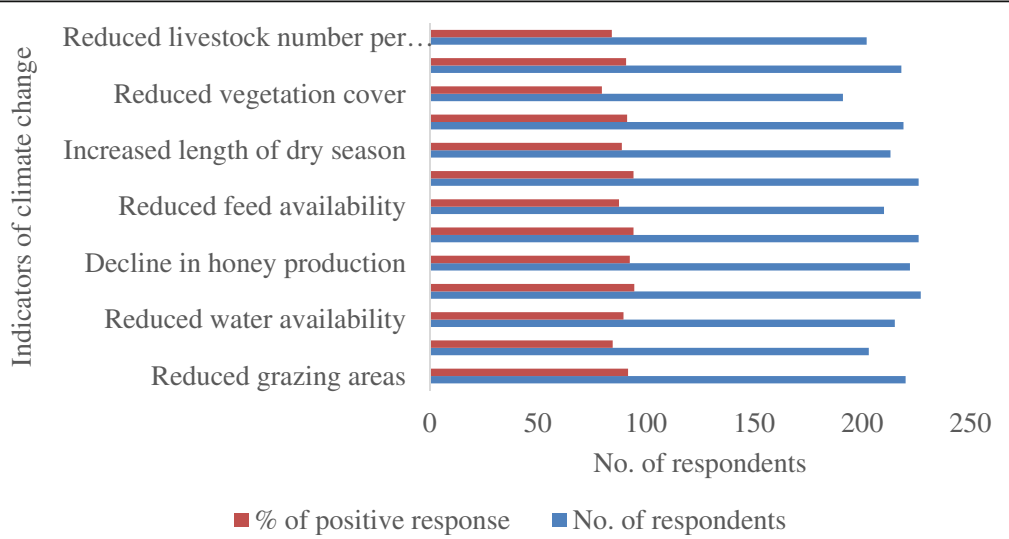

Fig. 4 Communities' perceptions related to indicators of climate change in Sidama southern Ethiopia 
Table 1 Respondents' perceptions on land size owned in hectare at present as compared to 40-50 years ago in Sidama South Ethiopia

\begin{tabular}{|c|c|c|c|c|c|}
\hline \multicolumn{3}{|c|}{ Land size owned in ha $40-50$ years ago } & \multicolumn{3}{|c|}{ Land size owned in ha at present } \\
\hline Land size & No. of respondents $(N=240)$ & $\%$ respondents & Land size & No. of respondents $(N=240)$ & $\%$ of positive response \\
\hline $0-0.4$ & 110 & 45.8 & $0-0.4$ & 2 & 0.8 \\
\hline $0.5-2.4$ & 20 & 8.3 & $0.5-2.4$ & 80 & 33.3 \\
\hline $2.5-3$ & 42 & 17.5 & $2.5-3$ & 79 & 32.9 \\
\hline $3.1-4$ & 41 & 17.1 & $3.1-4$ & 46 & 19.2 \\
\hline $4.1-5$ & 12 & 5.0 & $4.1-5$ & 19 & 7.9 \\
\hline $5.1-6$ & 12 & 5.0 & $5.1-6$ & 8 & 3.3 \\
\hline \multirow[t]{3}{*}{$6.1-7$} & 3 & 1.3 & $6.1-7$ & 4 & 1.7 \\
\hline & & & $7.1-8$ & 1 & 0.4 \\
\hline & & & $8.1-9$ & 1 & 0.4 \\
\hline
\end{tabular}

between 1973 and 2015 (Figs. 5 and 6). The agricultural land use had gained 433 ha from the other land use types (Table 5). Overall, the forestland type was the dominant LULC type between 1973 and 2015 (Fig. 5). The results showed an increase in shrubland size between 1973 and 1986 though it was in a downward trend from 2000 to 2015 (Fig. 5). In contrast, we found an expansion of bushland cover between 1973 and 2000 (Fig. 5). Overall, about $15.9 \%$ of the forestland cover was converted to other land use types while only $19.36 \%$ of the original grassland was remained unchanged in 2015 (Table 3).

\section{Land use/land cover analysis}

Figure 7 presents the overall changes per land use type based on satellite imageries analysis. The change matrix analysis showed that about 1633.5 ha $(59.8 \%)$ of the study areas experienced land use/cover changes over the last four to five decades (1973-2015). The results showed a considerable reduction in forestland between 1973 and 1986, which was accounted for 534.059 ha (32.5\%) (Fig. 7). By contrast, forestland was increased by 29\% between 2000 and 2015 (Fig. 7). The analysis confirmed that grassland was in a downward trend throughout the study periods, whereas the agricultural land

Table 2 Community's perception of land use/land cover changes comparison 40-50 years ago versus the present situation in Sidama, South Ethiopia

\begin{tabular}{|c|c|c|}
\hline Respondents' views & No. of respondents & $\%$ of positive response \\
\hline Low number of livestock in the past $40-50$ years & 198 & 82.5 \\
\hline Availability of abundant grasses in the past $40-50$ years & 210 & 88.7 \\
\hline Shift in livestock feeding strategy in response to feed shortage & 216 & 90 \\
\hline $\begin{array}{l}\text { Natural pastures, wetlands, bamboo leaves, enset leaves, and tree leaves are major sources of livestock } \\
\text { feed resources }\end{array}$ & 209 & 87.1 \\
\hline Availability of abundant desirable grasses and herbs in the past $40-50$ years & 185 & $77.1 \%$ \\
\hline $\begin{array}{l}\text { Trees/shrubs such as Yushania alpina (mountain bamboo), Erica arborea, Hypericum revolutum, Hagenia } \\
\text { abyssinica, and llex mitis are major livestock feeds }\end{array}$ & 232 & 96.7 \\
\hline Some 40-50 years ago, more areas of forestlands were visible with lesser proportions of grazing and croplands & 222 & $92.5 \%$ \\
\hline Less number of livestock per unit area was common in the past $40-50$ years & 226 & 94.2 \\
\hline Very low livestock number per household at present versus $40-50$ years & 228 & $95 \%$ \\
\hline Changes in land cover resulted in land degradation & 222 & 92.5 \\
\hline EECMY involved in land resource conservation & 240 & 100 \\
\hline High livestock and excess milk production $40-50$ years ago versus current years & 203 & 84.6 \\
\hline High crop yield per unit land some $40-50$ years ago versus current years & 224 & 93.3 \\
\hline $\begin{array}{l}\text { Deforestation, overgrazing, soil erosion, and land degradation are major causes of land use/land } \\
\text { cover changes }\end{array}$ & 226 & 91.3 \\
\hline Major portion of the land is covered by crop and vegetable at present & 214 & 89.2 \\
\hline Grazing lands were drastically reduced at present versus 40-50 years ago & 191 & 79.6 \\
\hline
\end{tabular}




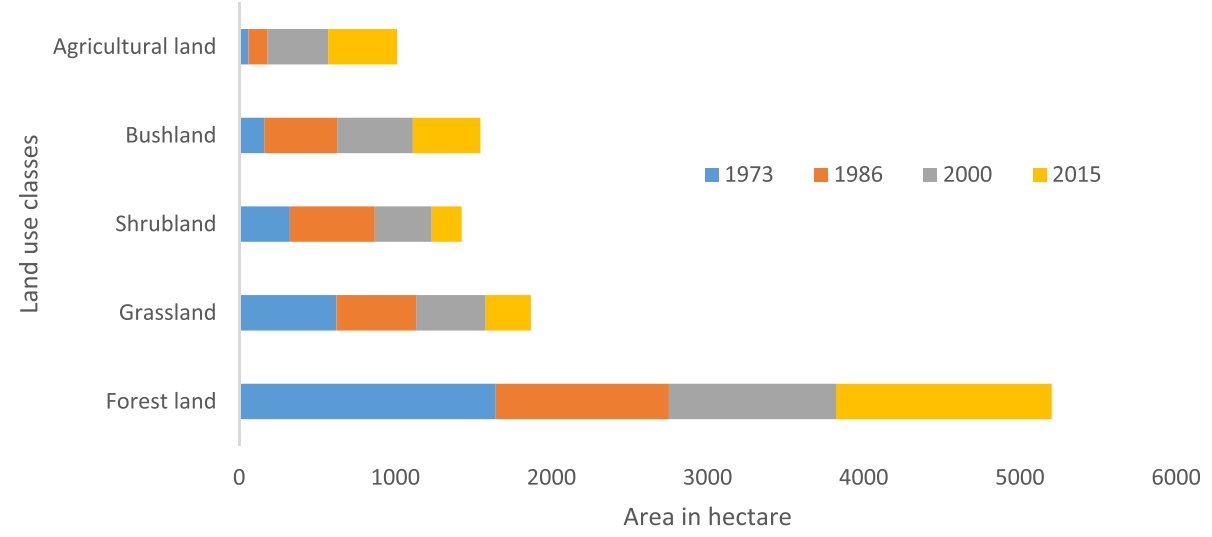

Fig. 5 Percent of land use land/cover change for each year in different land use types of the study area between 1973 and 2015

showed an upward trend (Fig. 7). A similar increase was observed in the bushland cover type at different periods by $191.99 \%$ (1973-1986) and 3.6\% (1986-2000) (Fig. 7). However, we recorded inconsistences with regard to the patter of shrubland with initial expansion and decline thereafter between 1986 and 2015 (Fig. 7).

\section{Persistence of LULC classes}

Our results showed that all categories of land use/ cover types had experienced more gain than persistence gp with a score of more than 1 except forestland (0.36) (Table 4). The current analysis showed that agricultural land had the highest (49) gp ratio, while that of forestland was the least between 1973 and 1986 (Table 4). Overall, the results showed a similar trend with regard to gp ratio across all land use types, except that of forestland (Table 4). The analysis revealed that the gp values for the different land use classes (i.e., grassland, shrubland, bushland, and agricultural land) were greater than 1, although the value was less than 1 in the case of forestland (Table 4). The highest lp ratio (22.56) was observed in the case of agricultural land followed by bushland (14.24) and shrubland (8.03) (Table 4). The values of net-change to persistence $(\mathrm{np})$ ratios were negative for forestland, grassland, and shrubland over the last four to five decades (Table 4). The value of np ratio for the agricultural land cover type was the highest among all land use/cover types with a net increase by 50 times since 1973. Likewise, the bushland cover types also experienced a net increase in size (Table 4).

Appendix 3 presents the sum of persistence of all land use/land cover classes in terms of percent resistance by the different landscapes to change. Appendix

\section{Land use/cover change (1973-2015)}

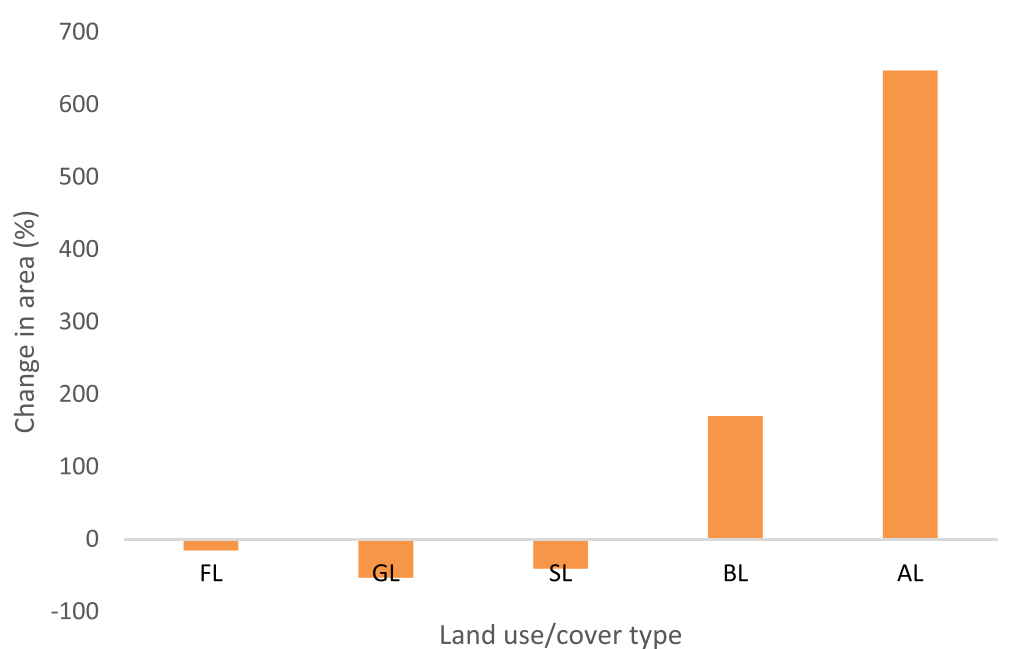

Fig. 6 Diagrammatic illustration of land use/cover change in ha during the last four to five decades (1973-2015) in the study area, Sidama highlands of southern Ethiopia 
Table 3 Land use/cover change matrix showing land encroachment (in \%) in the study area, Sidama, South Ethiopia between 1973 and 2015

\begin{tabular}{|c|c|c|c|c|c|c|c|}
\hline \multirow{2}{*}{$\frac{\text { Years }}{2015}$} & \multicolumn{7}{|l|}{1973} \\
\hline & Land use/cover category & $\mathrm{FL}$ & $\mathrm{GL}$ & $\mathrm{SL}$ & $\mathrm{BL}$ & $\mathrm{AL}$ & \\
\hline & & $\%$ & $\%$ & $\%$ & $\%$ & $\%$ & $\%$ Total loss \\
\hline & $\mathrm{FL}$ & 57.94 & 7.37 & 6.45 & 13.89 & 14.35 & 42.06 \\
\hline & $\mathrm{GL}$ & 33.34 & 19.36 & 7.88 & 20.88 & 18.54 & 80.64 \\
\hline & SL & 40.47 & 12.81 & 8.89 & 17.30 & 20.54 & 91.10 \\
\hline & $\mathrm{BL}$ & 60.59 & 5.92 & 4.79 & 11.30 & 17.38 & 88.69 \\
\hline & $\mathrm{AL}$ & 49.35 & 8.90 & 8.87 & 19.5 & 13.40 & 86.60 \\
\hline & Total 2015 (\%) & 50.51 & 48.2 & 60.9 & 273.5 & 764.8 & \\
\hline & Gain (ha) & 450.86 & 172.85 & 163.4 & 413.4 & 433.0 & \\
\hline & Net (ha) & -223.49 & -310.70 & -122.51 & 273.6 & 383.1 & \\
\hline & Persistence (\%) & 57.9 & 19.4 & 8.9 & 11.3 & 13.4 & \\
\hline & NP (ha) & -0.24 & -2.68 & -4.39 & 15.35 & 49.64 & \\
\hline
\end{tabular}

Figures in italic show persistence (unchanged)

$F L$ forestland, $G L$ grassland, $S L$ shrubland, $B L$ bushland, $A L$ agricultural land, NP net change to persistence ratio

3 portrays the temporal changes in land use over the last four to five decades. Nearly $60 \%$ of the landscape had experienced a transition from one land use to another. However, about $72 \%$ of this transition occurred due to swap changes where a coinciding gain and loss occurred among land use classes. As indicated in Appendix 3, the overall persistence was $41.21 \%$ between 1973 and 2015. The existing analysis confirmed that persistence value is lower than the values for the total change, swap, and gain/loss. Forestland in general experienced the highest persistence values during the three study periods (Appendix 3).

\section{Accuracy assessment}

Our results showed that the overall accuracies for the four reference years were within the range of $77.59 \%$ to $86.51 \%$ with the Kappa statistic between 0.6912 and 0.8031 (Table 5). The results of the Kappa statistics showed a good level of agreement for each of the four classified images. Table 5 shows users' and producers' accuracies for the forestland (FL), grassland (GL), shrubland (SL), bushland (BL), and agricultural land (AL) cover types between 1973 and 2015.

Some of the forestland samples were identified as grassland, shrubland, bushland, and agricultural land in

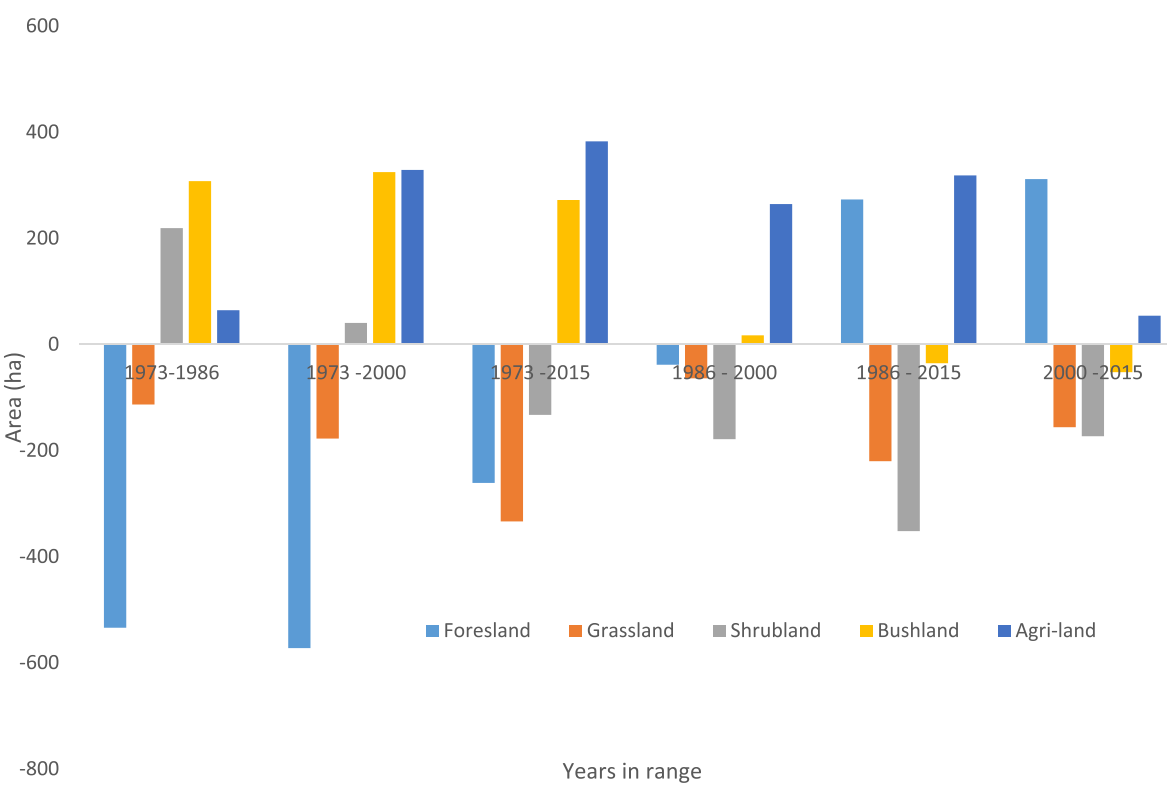

Fig. 7 Area of land cover changes (in ha) and \% increase or decrease for the different reference years in Sidama, southern Ethiopia 
Table 4 Gain-to-persistence (gp), loss-to-persistence (lp), and net change-to-persistence (np) ratios of LULC categories for the 19731986, 1986-2000, and 2000-2015 periods

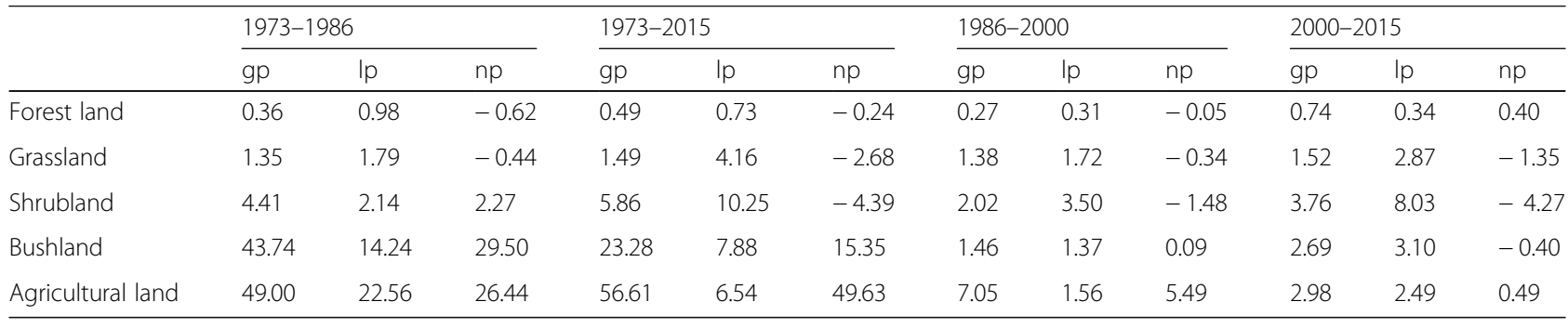

1973. However, FL users' accuracy was $82.5 \%$ (Table 5). On the other hand, GL and BL cover types achieved users' accuracies of 92.59 and 100\%, respectively (Table 5). In the second column of Table 4, out of the total 27 randomly generated reference samples for grassland, 25 samples were correctly classified as grasslands, while only 2 samples were misclassified as shrubland cover type. Similarly, in the third row of Table 4, out of the total six reference samples, two samples of shrubland were misclassified as forest and grassland and four samples were correctly classified.

In 2015, out of the total 63 randomly generated reference samples for forestland cover type, 56 were correctly classified as forestland yielding users' accuracy of $88.89 \%$. Similarly, out of 13 randomly generated samples for grassland, 11 were correctly classified as grassland, which gives $84.62 \%$ user's accuracy (UA). In the same manner, out of eight randomly generated samples, eight were classified correctly as SL giving $100 \%$ UA. For the summary of error matrices of classification accuracies of all study years, see Table 6 .

\section{Discussion}

The use of local perception and LULC changes in understanding the effects of anthropogenic factors linked to climate change on mountain grassland ecosystems is crucial for future management and conservation of these ecosystems. In the current study, using local perceptions and analyses of remotely sensed images, we generated evidence of human-climate induced patterns of LULC dynamics supported by GIS technology in the mountain grasslands of Sidama. In the mountain grasslands of Sidama, perceptions of respondents indicate that land use/cover changes are occurring as a result of multiple drivers with potential consequences of climate change. Observations of respondents and analyses of remotely sensed images further suggest the existence of extensive changes in land use cover dynamics with increasing drought, deforestation, and expansion of agricultural lands. These reflect rapid changes in human population growth, land tenure, and associated pressures on the environment with consequences of major shifts in land use, which also agree with Chase et al. (1999). Observations of respondents indicate that land use/cover dynamics in the mountain grasslands of Sidama in South Ethiopia is accelerated by drought and changes in the timing of rain. Among others, experiences of respondents show that the rapid growth of human population, expansion of settlements, and increased mountain side farming are major factors for the loss of forest landscape.

The issue of unequal land distribution under the Feudal system prior to the 1970s was resolved by the 1975 land proclamation (Dessalegn 1984). Following the land

Table 5 Accuracy assessment of report for 1973 and 2015 reference data in the study areas, Sidama, South Ethiopia

\begin{tabular}{|c|c|c|c|c|c|c|c|c|c|c|c|c|c|c|}
\hline \multicolumn{8}{|c|}{ Year of reference data 1973} & \multicolumn{7}{|c|}{ Year of reference data 2015} \\
\hline Land cover type & $\mathrm{FL}$ & $\mathrm{GL}$ & $\mathrm{SL}$ & $\mathrm{BL}$ & $\mathrm{AL}$ & Total & UA (\%) & $\mathrm{FL}$ & $\mathrm{GL}$ & SL & $B L$ & $\mathrm{AL}$ & Total & UA (\%) \\
\hline $\mathrm{FL}$ & 66 & 4 & 5 & 4 & 1 & 80 & 82 & 56 & 0 & 4 & 1 & 2 & 63 & 88.89 \\
\hline $\mathrm{GL}$ & 0 & 25 & 2 & 0 & 0 & 27 & 93 & 0 & 11 & 0 & 2 & 0 & 13 & 84.62 \\
\hline SL & 1 & 1 & 4 & 0 & 0 & 6 & 67 & 0 & 0 & 8 & 0 & 0 & 8 & 100 \\
\hline$B L$ & 0 & 0 & 0 & 1 & 0 & 1 & 100 & 5 & 0 & 0 & 14 & 1 & 20 & 70 \\
\hline $\mathrm{AL}$ & 0 & 0 & 0 & 0 & 0 & 0 & 0 & 1 & 0 & 1 & 0 & 20 & 22 & 90.91 \\
\hline Column total & 67 & 30 & 11 & 5 & 1 & 114 & & 62 & 11 & 13 & 17 & 23 & 126 & \\
\hline PA (\%) & 98 & 83 & 36 & 20 & 0 & & & 90 & 94 & 61.54 & 82.35 & 86.96 & & \\
\hline \multicolumn{8}{|c|}{$\begin{array}{l}\text { Overall classification accuracy }=84.21 \% \text {, overall Kappa statistics }=0.6962 \\
\text { Total no. of samples } 114 \text {, accurate samples } 96\end{array}$} & \multicolumn{7}{|c|}{$\begin{array}{l}\text { Overall classification accuracy }=86.51 \text {, Kappa statistic }=0.8031 \\
\text { PA }=\text { producer's accuracy, UA }=\text { user's accuracy } \\
\text { Total no. of samples } 126 \\
\text { No. of accurate samples } 109\end{array}$} \\
\hline
\end{tabular}


Table 6 Summary of the error matrices of classification accuracies of 1973, 1986, 2000, and 2015 in Sidama, South Ethiopia

\begin{tabular}{|c|c|c|c|c|c|c|c|c|c|c|c|c|c|c|c|c|}
\hline \multirow[t]{2}{*}{ Class } & \multicolumn{4}{|c|}{ Producers' accuracy (PA) } & \multicolumn{4}{|c|}{ Users' accuracy (UA) \% } & \multicolumn{4}{|c|}{ Overall accuracy \% } & \multicolumn{4}{|c|}{ Kappa coefficient } \\
\hline & 1973 & 1986 & 2000 & 2015 & 1973 & 1986 & 2000 & 2015 & 1973 & 1986 & 2000 & 2015 & 1973 & 1986 & 2000 & 2015 \\
\hline $\mathrm{FL}$ & 98.5 & 81.25 & 86.05 & 90.32 & 82.5 & 68.42 & 78.7 & 88.89 & & & & & & & & \\
\hline $\mathrm{GL}$ & 83.33 & 67.44 & 71.43 & 94.00 & 92.59 & 76.32 & 78.9 & 84.62 & 84.21 & 78.21 & 77.59 & 86.51 & 0.70 & 0.70 & 0.70 & 0.80 \\
\hline$S L$ & 36.36 & 88.89 & 41.67 & 61.54 & 66.67 & 86.49 & 83.3 & 100 & & & & & & & & \\
\hline$B L$ & 20 & 76.92 & 84.00 & 82.35 & 100 & 71.43 & 75. & 70. & & & & & & & & \\
\hline$A L$ & & 16.67 & 80.00 & 86.96 & & 100. & 75. & 90.9 & & & & & & & & \\
\hline
\end{tabular}

reform decree in 1975, the local communities had ensured access to land. The 1975 land reform created an opportunity where landless peasants allocated farmlands that changed the form of ownership. Changes in land ownership from the landlords to peasantry lead to the exploitation of the land for agriculture that probably accelerated land use/cover changes. Likewise, the use of forest products for fuel and house construction greatly contributed to land cover changes. Overall, the demand for increased crop production for household consumption might exacerbate the processes of forest loss.

Perceptions of respondents regarding land use/cover dynamics are consistent with the current satellite imagery analyses. The results from satellite imagery analysis also confirm respondents' perceptions of high forest cover in the past 40 to 50 years. Moreover, respondents' reflections of vast grasslands in the past 40 to 50 years are generally consistent with the results of satellite imagery analysis. The reflections of respondents regarding the expansion of mountain side farming are disclosed by satellite imagery analyses, suggesting a dramatic increase in cropland between 1973 and 2015.

Observations of respondents reflect that they have a detailed knowledge of sharing their experiences about the impact of climate change using local indicators. These local indicators as indicated by respondents include increased temperature and livestock diseases, reduced milk production, decline in livestock feed resources and limited water availability, changes in the timing of rain, dried up of wet lands, and frequent droughts. The probable causes of land degradation and low productivity could be attributed to excessive human interference and over-exploitation of natural resources accelerating patterns of land use/cover changes.

The encroachment of cultivation into mountain grassland areas are major causes of land use/cover changes in the study areas. The results suggest that the encroachment of crop cultivation is increased by $646.74 \%$ between 1973 and 2015 with a considerable damage on the forest cover. The perceptions of respondents indicate that the demand for family's food production is the major driver for the expansion of agricultural land in mountain areas. Gibbs et al. (2010) have reported a similar case where the high demand for food and fuel is a major factor for the expansion of crop cultivation into mountain areas in developing countries. Generally, the growth of human population and agrarian land transformation are major contributing factors.

Observations of respondents suggest that the processes of land use/cover changes are more manifested in terms of shifts in forest cover, shrinkage of grazing lands, and increase in crop fields. Respondents' perceptions of deforestation, major shifts in grazing lands, and increased agricultural fields into mountain areas are also confirmed by the existing satellite image analyses. Respondents further believed that there are enormous ongoing changes with regard to the impact on forest and grassland resources. Generally, respondents stated that livestock number has exceeded the capacity of the land due to population growth and expansion of crop cultivation. Perceptions of reduced forest cover and available grazing lands are consistent with our results from the remotely sensed images. Our results indicate that although the forest cover initially showed a downward trend, there had been an improvement in forest cover of the study areas since 2000.

Quantitative results of the existing change analysis over the last 42 years during three different periods (1973-1986, 1986-2000, and 2000-2015) and change matrix between 1973 and 2015 revealed the extent of changes in terms of land use dynamics. In general, the trends in forest cover, grassland, and shrubland show incessant decline. Hence, the LULC change assessments indicate that $119.58 \%$ of the area underwent a transition between the natural and human-dominated activities. This increase in agricultural land reinforces the idea that human economic activities are the major driving factors behind LULC changes (Wang et al. 2008). Generally, crop land increased by 433.02 ha, which was gained from other land use types. This suggests that as human population grows, mountain side forests and grassland resources might be affected adversely with the expansion of crop cultivation. Furthermore, respondents' observations suggest that as the growth of human population continues, the demand for food will rise. Zeleke and Hurni (2001) have also argued that changes in mountain side forests and grassland covers is a common phenomenon in other places with similar settings due to 
human interferences. Similarly, Shiferaw (2011) has reported the loss of forest cover due to the expansion of agriculture in South-Wollo highlands of Ethiopia.

Our results suggest that the growth of human population, changes in land use policy, and expansion of agriculture are major reasons for the loss of mountain grasslands in the study areas. The growth of human population and modification of the natural environment to drive livelihood needs most likely caused damage to forests that further facilitated bush encroachment as a result of secondary succession following disturbances. Our results indicate that major forest loss occurred between 1973 and 2000. The probable explanation could be the reallocation of lands to peasants following the 1975 land proclamation in Ethiopia (Dessalegn 1984).

Our results are in agreement with the report by Braimoh (2006), suggesting that a gp ratio of greater than 1 is an indication of the possibility for a landscape category to expand beyond its original size. Related to our finding, the probable explanation for the greater than 1 values of gp could be a result of the exposure of a given landscape toward transition (Braimoh, 2006). This suggests a considerable change in terms of the different land use types as oppose to their original sizes. In contrast, the less than $1 \mathrm{gp}$ value for the forest cover suggests that the forest resource is the most vulnerable land use type.

In connection with LULC persistence, the negative values for the net-change in the case of forestland, grassland, and shrubland covers reflect the net loss in the different land use classes. The probable reason for higher ratio of lp (i.e., > 1) denotes the tendency for a class of land use type toward transition, which is also consistent with the report by Braimoh (2006). Throughout the study period, the forestland displayed a lower amount of loss. This is an indicator of a better chance of expansion in terms of forestland with a minimal tendency for loss. The values of lp ratio for the grassland, shrubland, bushland, and agricultural land were greater than one, suggesting their exposure to transition.

We found that all land use/cover classes had greater than $1 \mathrm{lp}$ values with exception of forestland. Overall, the agricultural land type experienced the highest lp ratio (22.56) followed by the bushland (14.24) and shrubland (8.03) cover types, suggesting that mountain side cultivation as the most driving force for the loss of forests and grassland resources. Likewise, previous studies (Lemenih et al. 2004; Hailu et al. 2015) have shown that the expansion of agriculture is a major factor for the loss of forest cover in Ethiopia. According to Foody (2001), land use land cover changes are strongly related to the patterns of rainfall.

The existing analysis indicates that the net change within the landscape between 1973 and 2015 is accounted for $48 \%$. On the other hand, the observed total change within the landscape is 119.58 , suggesting that both swap and net changes are vital in recognizing the total conversions within a landscape. Generally, analyses of land use conversion that only consider the net change might weaken the existing total changes of the ecosystem. Thus, our results confirm that the swap changes that had taken place between 1973 and 2015 are attributed to the gains and losses in the different landscapes.

Generally, our results are justified using the actual LULC maps of 1973, 1986, 2000, and 2015 with an overall accuracies of $86.5 \%$ and a Kappa statistic of 0.803 , which is within the range of accuracies reported in previous studies (Echeverria et al. 2008; Kamusoko et al. 2011). The LULC patterns and changes in the mountain grasslands of Sidama in South Ethiopia are reflective of the various prospects and restraints for the use and conservation of mountain grassland ecosystems in the region.

\section{Conclusion}

The significant amount of spatial changes among the different land use/cover types over the last four to five decades mainly contributed to the ongoing degradation of mountain grassland ecosystems in Sidama, South Ethiopia. In 1973, the forestland cover was the dominant land use/cover type that accounted for $58 \%$ of the studied landscapes, followed by grassland (22\%), bushland (16\%), and Shrubland (12\%). Four decades later in 2015, the proportions of forest, grassland, shrubland, and bushland covers were $50 \%, 11 \%, 7 \%$, and $16 \%$, respectively. On the other hand, the agricultural landscape was increased from 2\% in 1973 to $16 \%$ in 2015 with a net gain of $14 \%$, while the net gain for the forest cover was $8.2 \%$. The replacement of natural forest by agricultural landscape exposed top soils to erosion with major consequences on this ecosystem.

Based on the results of GIS and remotely sensed analyses versus local communities' perceptions, it can be concluded that the mountain grassland ecosystems of Sidama had already altered in terms of land use/cover dynamics over the last four to five decades. The LULC dynamics in the study area was evident by the declines in terms of forest cover (15.9\%), grassland (53.57\%), and shrubland (40.96\%) at the end of 2015. Communities' perceptions confirmed that the major drivers of LULC dynamics were attributed to changes in land tenure, increased population pressure, excessive exploitation, increased agricultural landscapes, overgrazing, impacts of climate change, and the high demand for wood products that resulted in deforestation. The results indicate a gradual transition in land use/cover changes caused by human-climate induced factors that calls for proper management and conservation of mountain grassland ecosystem in the study areas. 


\section{Appendix 1}

Table 7 Satellite imagery used for the multi-temporal change detection in Sidama, South Ethiopia

\begin{tabular}{|c|c|c|c|c|c|c|c|}
\hline No. & Acquisition date & Sensor & Spatial resolution & Path/Row & Satellite & Number of bands & Radiometric resolution \\
\hline 1 & $23 / 12 / 2015$ & OLI-TIRS & 30 & $168 / 55$ & Landsat 8 & 11 & 16 bits \\
\hline 2 & 05/02/2000 & ETM+ & 30 & $168 / 55$ & Landsat 5 & 7 & 8 bits \\
\hline 3 & 21/01/1986 & TM & 28 & $168 / 55$ & Landsat 5 & 7 & 8 bits \\
\hline 4 & 31/01/1973 & MSS & 57 & $181 / 55$ & Landsat 1 & 4 & 8 bits \\
\hline
\end{tabular}

\section{Appendix 2}

Table 8 Land use/land cover classes considered and their description in Sidama, South Ethiopia

\begin{tabular}{lll}
\hline No. & $\begin{array}{l}\text { Land use/land } \\
\text { cover classes }\end{array}$ & Description \\
\hline 1 & Forest land & Areas covered by natural and man-made trees with minimum size of $\geq 0.5$ ha \\
2 & Grassland & All areas covered with natural grass and small shrubs dominated by grasses \\
3 & Shrubland & Vegetation dominated by shrubs, often also including grasses, herbs, and geophytes \\
4 & Bushland & $\begin{array}{l}\text { Areas covered with scattered trees and bushes along the study landscape. Small patches of forests ( }<0.5 \text { ha) are } \\
\text { also included in this category }\end{array}$ \\
5 & Agricultural land & $\begin{array}{l}\text { All land dedicated to the production of cultivated crops. Area of land prepared for growing agricultural crops. This } \\
\text { category includes areas currently under crop, and land under preparation }\end{array}$ \\
\hline
\end{tabular}

\section{Appendix 3}

Table 9 Summary of LULC changes expressed as a percentage of the landscape (1973-1986, 1986-2000, 2000-2015)

\begin{tabular}{|c|c|c|c|c|c|c|c|c|c|}
\hline & & & Persistence & Gain & Loss & $\begin{array}{l}\text { Total } \\
\text { change }\end{array}$ & Swap & $\begin{array}{l}\text { Absolute value of } \\
\text { net change }\end{array}$ & Remarks \\
\hline & 1973 & 1986 & & & & & & & \\
\hline Forestland & 58 & 40 & 29.63 & 10.67 & 29.03 & 39.7 & 21.34 & 18.36 & \\
\hline Grassland & 22 & 19 & 7.89 & 10.62 & 14.12 & 24.74 & 21.24 & 3.50 & \\
\hline Shrubland & 12 & 20 & 3.64 & 16.07 & 7.79 & 23.86 & 15.58 & 8.28 & \\
\hline Bushland & 6 & 17 & 0.38 & 16.62 & 5.41 & 22.03 & 10.82 & 11.21 & \\
\hline Agricultural land & 2 & 4 & 0.09 & 4.41 & 2.03 & 6.44 & 4.06 & 2.38 & \\
\hline \multirow[t]{2}{*}{ Total } & 100 & 100 & 41.63 & 58.37 & 58.37 & 116.74 & 73.04 & 43.73 & \\
\hline & 1986 & 2000 & & & & & & & \\
\hline Forestland & 40 & 39 & 30.63 & 8.25 & 9.64 & 17.89 & 16.5 & 1.39 & \\
\hline Grassland & 19 & 16 & 6.81 & 9.38 & 11.70 & 21.08 & 18.76 & 2.32 & \\
\hline Shrubland & 20 & 13 & 4.39 & 8.87 & 15.36 & 24.23 & 17.74 & 6.49 & \\
\hline Bushland & 17 & 18 & 7.16 & 10.44 & 9.83 & 20.27 & 19.66 & 0.61 & \\
\hline Agricultural land & 4 & 14 & 1.75 & 12.33 & 2.73 & 15.06 & 5.46 & 9.6 & \\
\hline \multirow[t]{2}{*}{ Total } & 100 & 100 & 50.74 & 49.26 & 49.26 & 98.52 & 78.12 & 20.41 & \\
\hline & 2000 & 2015 & & & & & & & \\
\hline Forestland & 39 & 50 & 29.00 & 21.51 & 9.81 & 31.32 & 19.62 & 11.7 & \\
\hline Grassland & 16 & 11 & 4.19 & 6.38 & 12.04 & 18.42 & 12.76 & 5.66 & \\
\hline Shrubland & 13 & 7 & 1.47 & 5.52 & 11.80 & 17.32 & 11.04 & 6.28 & \\
\hline Bushland & 18 & 16 & 4.28 & 11.52 & 13.25 & 24.77 & 23.04 & 1.73 & \\
\hline Agricultural land & 14 & 16 & 4.05 & 12.08 & 10.10 & 22.18 & 20.2 & 1.98 & \\
\hline Total & 100 & 100 & 43.00 & 57.00 & 57.00 & 114 & 86.66 & 27.35 & \\
\hline
\end{tabular}


Table 9 Summary of LULC changes expressed as a percentage of the landscape (1973-1986, 1986-2000, 2000-2015) (Continued)

\begin{tabular}{lllllllllll}
\hline & & & Persistence & Gain & Loss & $\begin{array}{l}\text { Total } \\
\text { change }\end{array}$ & Swap & $\begin{array}{l}\text { Absolute value of } \\
\text { net change }\end{array}$ & Remarks \\
\hline Forestland & 1973 & 2015 & & & & & & & & \\
Grassland & 58 & 50 & 34.00 & 16.50 & 24.68 & 41.18 & 33 & 8.18 & For the whole study period (1973 to 2015) \\
Shrubland & 22 & 11 & 4.25 & 6.33 & 17.70 & 24.03 & 12.66 & 11.37 & \\
Bushland & 12 & 7 & 1.02 & 5.98 & 10.46 & 16.44 & 11.96 & 4.48 & \\
Agricultural land & 2 & 16 & 0.65 & 15.13 & 5.12 & 20.25 & 10.24 & 10.01 \\
Total & 10 & 100 & 40.21 & 59.79 & 59.79 & 119.58 & 71.52 & 48.06 & \\
\hline
\end{tabular}

\begin{abstract}
Abbreviations
AL: Agricultural land; BL: Bushland; ERDAS: Earth Resources Data Analysis System; ETM+: Enhanced Thematic Mapper plus; FGD: Focus group discussions; FL: Forestland; GIS: Geographic information system; GL: Grassland; GPS: Geographical positioning system; HH: Household; LULC: Land use land cover; MSS: Multi-spectral scanner; OLI : Operational land imager; SL: Shrubland; SNNPRS: South Nations Nationalities and Peoples Regional State; SPSS: Statistical Package for Social Sciences; TIRS: Thermal infrared sensor; TM: Thematic mapper; UA: User's accuracy; UTM: Universal Transverse Mercator; WGS84: World Geodetic System 1984
\end{abstract}

\section{Acknowledgements}

The authors gratefully acknowledge the financial support received from Hawassa University through Dr. Ayana Angassa's research project. The authors also recognize that the local communities in the study areas deserve appreciation for their participation and cooperation during the research work.

\section{Funding}

This research work was funded by Hawassa University. Funding bodies have no role in the design of the study and data collection, analysis, and interpretation of data and writing of the manuscript.

\section{Availability of data and materials}

Data for this manuscript was collected through household survey; FGDs held with members of the community and remotely sensed images.

\section{Authors' contributions}

DD conducted the field research, analyzed the data, and drafted the manuscript. $A A n, A A b$, and AT designed the research, interpreted the results, and fully participated in the whole process of write-up of the manuscript. $A B$ dealt with the GIS and remote sensing and its interpretation. All authors revised the manuscript and read and approved the final version.

\section{Authors' information}

Denbeshu Debeko is a PhD candidate at Hawassa University. His research interest includes influence of grazing and climate on grassland ecosystems, indigenous knowledge, and animal nutrition. Hawassa University, College of Agriculture, Department of Animal and Range Sciences P.O.Box 05, Hawassa, Ethiopia.

Ayana Angassa is a Rangeland Ecologists at Botswana University of Agriculture and natural resources. His research interest includes influence of grazing and climate on grassland ecosystems, carbon sequestration, indigenous knowledge, invasive plant species, and sustainable management and conservation of natural resources. Private Bag 0027, Sebele, Gaborone, Botswana.

Aster Abebe is an Animal Nutritionist at Hawassa University. Her research interest includes the nutritional quality of forage plants, grazing effects, indigenous knowledge, invasive plant species, and sustainable management and conservation of natural resources. Hawassa University, College of Agriculture, Department of Animal and Range Sciences P.O.Box 05, Hawassa, Ethiopia.

Ashenaf Burka is GIS specialist at Hawassa University. His research interest includes natural resources management, environmental geography, and indigenous knowledge. Hawassa University, Wondo Genet College of Natural Resources and Forestry, Hawassa, Ethiopia.

Adugna Tolera is Nutritionist at Hawassa University. His research interest includes ruminant nutrition, the nutritional quality of forage plants, grazing effects, indigenous knowledge, and sustainable management and conservation of natural resources. Hawassa University, College of Agriculture, Department of Animal and Range Sciences P.O.Box 05, Hawassa, Ethiopia.

Ethics approval and consent to participate Not applicable.

\section{Consent for publication}

Not applicable.

\section{Competing interests}

The authors declare that they have no competing interests.

\section{Publisher's Note}

Springer Nature remains neutral with regard to jurisdictional claims in published maps and institutional affiliations.

\section{Author details}

${ }^{1}$ College of Agriculture, School of Animal and Range Sciences, Hawassa University, P.O. Box 05, Hawassa, Ethiopia. ${ }^{2}$ Wondo Genet College of Forestry and Natural Resource, School of Natural Resources and Environmental Studies, Hawassa University, Hawassa, Ethiopia. ${ }^{3}$ Department of Animal Science and Production, Botswana University of Agriculture and Natural Resources, Private Bag 0027, Gaborone, Botswana.

Received: 3 July 2018 Accepted: 10 October 2018

Published online: 26 October 2018

\section{References}

Abate T, Angassa A (2016) Conversion of savanna rangelands to bush dominated landscape in Borana, Southern Ethiopia. Ecol. Proceses.5:6.

Beniston M, Diaz HF, Bradley RS (1997) Climatic change at high elevation sites: an overview. Clim Chang 36:233-251 53, 231-243

Beniston M, Rebetez M (1996) Regional behavior of minimum temperatures in Switzerland for the period 1979-1993. Theor Appl Clim 53:231-243

Braimoh AK (2006) Random and systematic land-cover transitions in northern Ghana. Agric Ecosyst Environ 2006(113):254-263

Bursa District Ministry of Agriculture office (MoA), 2014; Official data on Meno highland (unpublished data)

Chase TN, Pielke RA, Kittel TGF, Nemani RR, Running SW (1999) Simulated impacts of historical land cover changes on global climate in northern winter. Clim Dyn 16:93-105

Dessalegn R, (ed.) (1984). Agrarian reform in Ethiopia. Scandinavian Institute of African studies, Motala, Uppsala. Uppsala.

Echeverria C, Coomes DA, Hall M, Newton AC (2008) Spatially explicit models to analyze forest loss and fragmentation between 1976 and 2020 in southern Chile. Ecological Modelling 212(3-4):439-449. 
Ellis E, Pontius R (2007) Land use and land cover change. In: Cleveland CJ (ed) Encyclopedia of earth. Environmental Information Coalition, National Council for Science and the Environment, Washington, D.C. http://www.eoearth.org/ article/land-use_and_land-cover_change

Foody GM (2001) Monitoring the magnitude of land-cover change around the southern limits of the Sahara. Photogramm Eng Remote Sens 67:841-847

Gerlitz JY, Hunzai K, Hoermann B (2012) Mountain poverty in the Hindu-Kush Himalayas. J Dev Stud 33(2):250-265

Gibbs HK, Ruesch AS, Achard F, Clayton MK, Holmgren P, Ramankutty N, Foley JA (2010) Tropical forests were the primary sources of new agricultural land in the 1980s and 1990s. Proc Natl Acad Sci U S A 107:16732-16737

Gwet K (2002) Kappa statistic is not satisfactory for assessing the extent of agreement between raters. Stat Methods Inter-Rater Reliab Assess 76: 378-382

Hailu BT, Maeda EE, Heiskanen J, Pellikka P (2015) Reconstructing pre-agricultural expansion vegetation cover of Ethiopia. Appl Geogr 2015(62):357-365

Kamusoko C, Oono K, Nakazawa A, Wada Y, Nakada R, Hosokawa T, Tomimura S, et al. (2011) Spatial simulation modelling of future forest cover change scenarios in Luangprabang Province, Lao PDR. Forests, 2(3):707-729.

Körner C et al (2005) Chapter 24: mountain systems. In: Hassan R, Scholes R, Ash $N$ (eds) Ecosystems and human wellbeing: current state and trends. Island Press, Washington DC

Lu D, Mausel P, Brondízio E, Moran E (2004) Change detection techniques. Int J Remote Sens 25:2365-2401

Messerli B, Ives JD (eds) (1997) Mountains of the world: a global priority. Parthenon, New York

Owojori, A., Xie, H., 2005. Landsat image-based LULC changes of San Antonio, Texas using advanced atmospheric correction and object-oriented image analysis approaches. Paper presented at the 5th international symposium on remote sensing of urban areas, Tempe, AZ

Rosenfield GH, Fitzpatirck-Lins K (1986) A coefficient of agreement as a measure of thematic classification accuracy. Photogramm Eng Remote Sens 52(2): 223-227

Schroter D et al (2005) Ecosystem service supply and vulnerability to global change in Europe. Science 310(5752):1333-1337

Shiferaw A (2011) Evaluating the land use and land cover dynamics in Borena Wereda of South Wollo Highlands, Ethiopia. J Sustain Dev Africa 13:87-107

Singh A (1989) Review article digital change detection techniques using remotely-sensed data. Int J Remote Sens 10:989-1003

Spiegelberger T, Hegg O, Matthies D, Hedlund K, Schaffner U (2006) Long-term effects of short-term perturbation in a subalpine grassland. Ecology 87(8): $1939-44$

Thorsell J 2002. A global overview of mountain protected areas on the world heritage list: a contribution to the global theme study of world heritage natural sites. Working paper 6 world heritage, IUCN Larry Hamilton, Vice Chair-Mountains, World Commission on Protected Areas

Viera AJ, Garrett JM (2005) Understanding inter-observer agreement: the kappa statistic. Fam Med 37(360):363

Wang X, Zheng D, Shen Y (2008) Land use change and its driving forces on the Tibetan plateau during 1990-2000. Catena 72:56-66

Ward A, Dargusch P, Thomas S et al (2014) A global estimate of carbon stored in the world's mountain grasslands and Shrublands, and the implications for climate policy. Glob Environ Chang 28:14-24

Weng Q (2001) A remote sensing-GIS evaluation of urban expansion and its impact on surface temperature in the Zhujiang Delta, southern China. Inter J Rem Sens 22(10):1999-2014

Zeleke G, Hurni H (2001) Implications of land use and land cover dynamics for mountain resource degradation in the northwestern Ethiopian highlands. Mt Res Dev 21:184-191

\section{Submit your manuscript to a SpringerOpen ${ }^{\circ}$ journal and benefit from:}

- Convenient online submission

- Rigorous peer review

- Open access: articles freely available online

- High visibility within the field

- Retaining the copyright to your article

Submit your next manuscript at $\boldsymbol{\nabla}$ springeropen.com 